\title{
LA EXPERIENCIA DE LO BELLO Y LOS TALENTOS DEL ARTISTA: ACERCA DE LA REFLEXIÓN KANTIANA SOBRE ESTÉTICA Y ARTE
}

Romeld Bustamante Araujo

Pontificia Universidad Católica del Perú

El presente trabajo explora las características con las que Immanuel Kant determina qué es el sentimiento de lo bello experimentado en la naturaleza y en el arte. Tomando como punto de partida algunos elementos del surgimiento de la Estética en el siglo XVIII, se concentra en el estudio del trabajo artístico y muestra cómo el proceso creativo del artista se fundamenta en la producción y no en la reproducción mimética de la naturaleza. Con el propósito de explicar este tránsito, se revisan las reflexiones de uno de los antecesores de Kant: Moses Mendelssohn. Además, se señala cómo ambos pensadores divergen en sus teorías estéticas a pesar de que ambos concuerdan en rechazar la mímesis como principio de la producción artística. Finalmente, se determina la experiencia de lo bello como la complacencia en la conformidad a fin sin fin en el que se reproduce el libre juego de las facultades de imaginación y entendimiento, $y$ se atribuye al genio del artista el singular talento de adecuar su obrar en función a dicho juego.

Palabras clave:

Kant, Mendelssohn, mímesis, producción artística 
El estudio de la complacencia que se produce en el espíritu humano cuando se encuentra frente a la presencia de la bella naturaleza y del arte bello fue uno de los temas de investigación centrales durante la filosofía de la llustración. Las indagaciones sobre la belleza durante el siglo XVIII inauguraron una línea de pensamiento que derivó en lo que ahora conocemos como Filosofía del Arte. En el principio, sin embargo, la investigación sobre la belleza no correspondía únicamente al estudio del fenómeno artístico. La intención de los filósofos de la llustración interesados por lo bello apuntaba a reflexionar sobre la sensibilidad como el vehículo de conocimiento que marchaba en paralelo con el conocimiento lógico-racional del mundo. En 1735 Alexander G. Baumgarten publica Meditationes philosophicae de nonnullis ad poema pertinentibus', e introduce el término Estética para designar a la disciplina que de manera específica y autónoma se establecería como la ciencia del conocimiento sensitivo. Esta nueva disciplina se encargaría de explicar qué es lo que sucede cuándo las representaciones sensibles alcanzan a observar perfección o belleza en un objeto.

De acuerdo con las investigaciones sobre el conocimiento sensitivo en el siglo $\mathrm{XVIII}$, la belleza era el punto en el que convergían la naturaleza y el arte. De aquí que durante esta época el proceso creativo del artista haya despertado gran interés. Examinar el trabajo artístico y establecer cuáles eran los talentos que al genio creativo le permitían generar mediante sus obras sentimientos de complacencia en lo bello, parecía dar la clave para establecer cuál era el fundamento de la belleza. Una de las ideas que se planteó como criterio para explicar cómo la producción artística es capaz de generar complacencia desinteresada tal como lo hace la naturaleza, provenía de la tradición filosófica que postulaba que el secreto de la producción artística consistía en el principio de imitación de la naturaleza. Este mismo principio fue uno de los que se usó para aprehender el fenómeno artístico por la vía de la sistematización de las producciones artísticas. Charles Batteaux, a mediados del siglo XVIII, clasificó el proceso creativo utilizando la imitación de la naturaleza como principio de la producción artística. De acuerdo a su sistema, las artes quedaban clasificadas así: aquellas que deleitasen serían bellas artes (artes visuales, el arte verbal y

' Baumgarten, Alexander, "Reflexiones filosóficas en torno al poema", en: Cabot, Mateu (ed.), Belleza y verdad. Sobre la estética entre la llustración y el Romanticismo, Barcelona: Alba, 1999, pp. 23-78. 
la música) y aquellas con miras a su utilidad serían artes mecánicas. Además se estableció un tercer grupo (retórica y arquitectura) que conjugaba ambas cualidades, es decir, el placer que produjese y su utilidad. Lo que distinguía a las primeras era que su motivo versaba en agradar e imitar a la naturaleza ${ }^{2}$. La clasificación de Batteaux contó con gran difusión dentro de la academia interesada en utilizar las pistas que el arte brindaba para explicar el fenómeno de lo bello. Sin embargo, su trabajo fue también bastante criticado. El motivo principal de las críticas apuntaba a que la imitación de la naturaleza fuese el principio teórico del que se servía su clasificación. Durante la llustración la mímesis estaba dejando de ser un fundamento suficiente para explicar el fenómeno artístico, pero principalmente ya no era suficiente para explicar la experiencia de lo bello.

Uno de los críticos del trabajo de Batteaux fue Moses Mendelssohn, pensador en cuyas reflexiones nos detendremos con el propósito de advertir la transición que acontece en la investigación estética y la indagación sobre la producción artística durante la llustración. Señalaremos cómo sus investigaciones intentan establecer que, con el objetivo de generar la experiencia de lo bello, el trabajo artístico se fundamenta en la producción y no en la reproducción mimética de la naturaleza, y con esto pretende alejarse del principio que se evidencia en la clasificación de Batteaux. Sostendremos, sin embargo, que la producción artística dentro de las indagaciones de Mendelssohn todavía se encuentra sujeta al concepto de perfección, pasible de ser extraído y reproducido a partir de los productos de la naturaleza, evidenciando remanentes de una estética mimética. Luego nos concentramos en revisar las investigaciones que Emmanuel Kant realiza respecto de la facultad judicativa humana. Mostraremos que Kant ciertamente aísla de su teoría estética toda sujeción a conceptos de lo que deba ser lo bello, tanto para el ejercicio de la facultad del gusto en la naturaleza y en el arte, como para la producción artística. Mostraremos que, según Kant, la experiencia de lo bello es la complacencia en la conformidad a fin sin fin en el que se reproduce el libre juego de las facultades de conocimiento y se atribuye al genio del artista el singular talento de adecuar su obrar de acuerdo a dicho juego.

\footnotetext{
${ }^{2}$ Cf. Tatarkiewicz, Wladyslaw, Historia de seis ideas. Arte, belleza, forma, creatividad, experiencia estética, Madrid: Tecnos, 2002, p. 90.
} 


\section{\$ 1. Mendelssohn: indagaciones sobre el principio estético que comparten la naturaleza y el arte}

Si bien las investigaciones de Moses Mendelssohn no forman parte del canon erudito más sugerente que posee el repertorio filosófico occidental, sus indagaciones estéticas son ilustrativas del modo en que la teoría de la sensibilidad se convierte en una disciplina específica y autónoma de la experiencia de lo bello ${ }^{3}$. En 1757, Mendelssohn publicó un ensayo titulado Sobre los principios fundamentales de las bellas artes y las letras. En este texto Mendelssohn se propone dos objetivos: primero, intenta establecer un principio común a la producción artística en vista de que todas las artes son capaces de despertar vivamente sentimientos en el alma, de un modo en el que ninguna otra actividad lo consigue. Luego, con base en este principio, desarrolla una clasificación de las artes.

La investigación de Mendelssohn establece que el estudio de la sensibilidad tiene que ocuparse de indagar por los elementos que, tanto en la naturaleza como en el arte, consiguen despertar en el ser humano los más activos sentimientos. De acuerdo con sus reflexiones, ese elemento común es la belleza que encontramos tanto en la naturaleza como en el arte, pues funciona a manera de fundamento de todos nuestros impulsos naturales y "transforma en sentimiento el conocimiento especulativo de la verdad y encienden en nosotros una activa resolución"4.

Posteriormente, su indagación pretende establecer el modo en que la producción artística está vinculada con la creación de belleza. Para ello buscará el principio que "tienen en común todas estas obras de la creatividad humana para tender a coincidir en un único fin" 5 . Su investigación rechazará el intento de Batteaux de subsumir a las artes bajo el principio de imitación de la naturaleza. Encuentra que este principio, con miras al conocimiento de la sensibilidad humana, no resuelve nada en tanto la pregunta se podría trasladar también a la

${ }^{3}$ Cf. Cabot, Mateu, “La importancia de los estudios estéticos del siglo XVIII”, en: Cabot, Mateu (ed.), op. cit., p. 14.

${ }^{4}$ Mendelssohn, Moses, "Sobre los principios fundamentales de las bellas artes y las letras", en: Cabot, Mateu (ed.), op. cit., p. 240. 
contemplación de la naturaleza, y abriría el paso a indagar qué es aquello que en la naturaleza hace despertar a dicha facultad. En tanto quedó establecido que la naturaleza y el arte comparten la capacidad de activar los más vivos sentimientos en el alma, para Mendelssohn la pregunta más pertinente sería: ¿qué tienen en común las bellezas de la naturaleza y del arte, qué relación tienen con el alma humana para, de este modo, agradarle?

\section{§ 2. El ideal de perfección}

Mendelssohn señala que la perfección que encontramos en la naturaleza es lo que estimula el alma. La perfección sensible es llamada belleza, y es el medio por el cual nuestra alma se complace en la representación sensiblemente perfecta. Sostiene que una perfección sensiblemente representada por medio del arte es la esencia de las bellas artes. Una vez alcanzado este punto, Mendelssohn se centra en analizar el arte como producto de un determinado trabajo. Encuentra que si la perfección que el espectador tiene ante sí no es una perfección natural, sino una imitación de la naturaleza en el arte, inmediatamente este hecho "comporta algo desagradable, en cuanto nosotros desearíamos más bien, antes que la copia, el modelo agradable mismo"“. A saber, la perfección natural.

Sin embargo, si analizamos detenidamente qué es lo que nos dice Mendelssohn sobre la obra de arte y los talentos del artista, caeremos en la cuenta de que no considera que la singularidad del artista estribe en su capacidad para imitar la naturaleza. De aquí que señale que el desagrado que se pudiera encontrar en la obra de arte se ve menguado en tanto que el trabajo artístico posee, como veremos, otras características que generan la complacencia del espectador de arte.

La perfección es lo que el artista imita en sus obras; sin embargo, el trabajo del artista es distinto del trabajo del "gran artífice de la naturaleza". Este último tiene un objetivo propio, que es incluso incognoscible y distinto del que el artista posee. Lo que hace el artista es particularizar la creación en la 
representación de la perfección de la naturaleza y plasmarla en su trabajo. Esto es, realiza una obra bella. Los artistas "quieren representar un determinado objeto tal como Dios lo habría creado si la belleza sensible hubiese sido su más elevado fin último y ningún otro fin más importante le hubiese apartado de aquél"7. El artista tiene, como fin último, la belleza; por esto debe elevarse por encima de la naturaleza para captar aquel ideal que obtiene de todas las representaciones sensibles y plasmarlo en sus obras. Aunque su trabajo no es el de un mero imitador de la naturaleza, y pese al mayor esmero, no alcanza la perfección del genio. En efecto, "el genio demanda una perfección de todas las facultades del alma y una concordancia de las mismas en un único fin último" Los signos de esta perfección quedan esparcidos en las obras, y estos, a su vez, procuran un deleite incomparable con los de aquel común imitador?.

De este modo, tenemos que Mendelssohn no toma el arte únicamente como imitación de la naturaleza; si bien contempla este punto, señala que la obra de arte está íntimamente ligada con aquel que la produce. El ser humano no puede escudriñar en los fines que persigue la naturaleza, pues "la naturaleza tiene un plan inconmensurable"10. El artista únicamente actúa de acuerdo a sus fuerzas, se empeña en plasmar en un espacio limitado el ideal de la belleza natural y trabaja de acuerdo a "como lo habría representado la naturaleza si la belleza de este objeto limitado hubiera sido su único fin"". El genio del artista, cuyo fin último es la belleza, toma el ideal de la naturaleza y lo plasma en sus obras.

En resumen, notamos que Mendelssohn desarrolla una teoría del arte en la que señala que la experiencia estética está ligada al plano de la sensibilidad y que no puede ser determinada por el plano intelectual. Aborda este tipo de experiencia desde la belleza y la entiende como representación sensiblemente perfecta, pues es la única capaz de generar en el alma emociones como no puede hacerlo la perfección intelectual. Tenemos, además, que desarrolla una teoría artística donde toma en cuenta la experiencia y la producción artísticas

\footnotetext{
${ }^{7}$ lbid., p. 25I.

${ }^{8}$ Ibid., p. 248.

${ }^{9}$ Cf. ibid. 
como parte de todo el fenómeno del arte. De este modo, presta mucha atención a lo que ocurre con el artista en el momento de la producción de la obra. El objetivo de la producción artística se alcanza cuando las obras logran parecer naturaleza. Luego la plasma en su obra, dejando a su vez signos de "su mano maestra" que denotan su genio. Finalmente, nos indica que el genio del artista se mueve por sus propias reglas: el crítico de arte es el que las traduce en definiciones racionales.

Dentro del marco de su proyecto de evaluación crítica de la filosofía iniciado con la Crítica de la razón pura (I78I) y la Crítica de la razón práctica (1788), Emmanuel Kant publicó la Crítica de la facultad de juzgar (1790), tratado en el que también investiga sobre los elementos que componen las reflexiones sobre la Estética y la producción artística. El propósito central de Kant no es realizar una indagación pormenorizada del trabajo artístico, sino más bien señalar cómo es posible que nuestras facultades de conocimiento logren encontrar una particular conformidad a fin en determinados objetos, bien sean naturales o artísticos, a los que se les designa como bellos.

A continuación veremos como en el análisis de los juicios sobre la belleza, o juicios de gusto, Kant elabora una teoría que permite explicar cómo se produce en el ser humano la experiencia de lo bello y cuál es la relación de este sentimiento con los talentos del genio del artista.

\section{§ 3. La reflexión kantiana sobre la experiencia de lo bello}

En la Crítica de la facultad de juzgar Kant desarrolla una reflexión sobre la experiencia de lo bello dentro de la sección titulada "Deducción de los juicios estéticos puros". Esta reflexión tiene por base la primera sección: "La analítica de lo bello". Divide su análisis en cuatro momentos: según la cualidad (el juicio de gusto es desinteresado), según la cantidad ("bello es lo que place universalmente sin concepto"), según la relación de los fines (belleza es aquello que en la forma es conforme a fin pero sin la representación de un fin) y según la 
modalidad ("bello es lo que es conocido sin concepto como objeto de una complacencia necesaria") ${ }^{12}$.

Uno de los puntos fundamentales que Kant trabaja desde el primer momento de "La analítica de lo bello" es la relación entre el gusto y la belleza, así dirá: "gusto es la facultad de juzgar un objeto o un modo de representación por una complacencia o displacencia sin interés alguno. El objeto de tal complacencia se llama bello"' 3 . De este modo queda establecido que la belleza se capta a través de la facultad del gusto y que, a su vez, en un juicio de gusto se señala la belleza de un objeto.

\section{§ 3.I. El juicio de gusto}

Ahora bien, el juicio de gusto tiene un mecanismo por el cual funciona de manera similar a como lo hace un juicio de conocimiento. Sucede que con vistas a un conocimiento en general se ponen en obra nuestras facultades de conocimiento, a saber, imaginación y entendimiento. La primera, para la composición en lo múltiple de la intuición, y el entendimiento, para la unidad del concepto que unifica las representaciones ${ }^{14}$.

Algo semejante a lo señalado ocurre en el juicio de gusto, aunque en este plantea una diferencia que será fundamental. Sucede que este juicio no está determinado ni por un concepto de lo que deba ser el objeto de la representación, ni tampoco por el agrado en la sensación que produzca dicho objeto. En el juicio de gusto se produce una conformidad a fin sin fin en el juego de las facultades de conocimiento (imaginación y entendimiento), donde la imaginación no se subsume bajo un concepto (del entendimiento) de lo que deba ser el objeto ${ }^{15}$. Kant señala, además, que necesariamente en el juicio de gusto se produce, así como sucede con el conocimiento en general, una universal comunicabilidad, puesto que, imaginación y entendimiento concuerdan, aunque libremente, a propósito de la representación por la cual es

${ }^{12}$ Kant, Immanuel, Crítica de la facultad de juzgar, traducción de Pablo Oyarzún, Caracas: Monte Ávila, 1992, §§ I-22, B3-68.

${ }^{13}$ lbid., § 5, BI8.

${ }^{14}$ Cf. ibid., § 9.

${ }^{15}$ Cf. ibid. 
dado un objeto. Esto es, "debe poder comunicarse universalmente, porque el conocimiento, como determinación del objeto con la que deben concordar las representaciones dadas (en cualquier sujeto que fuese), es el único modo de representación válido para todos"16.

Ahora bien, antes de analizar la relación que Kant establece entre arte bello y naturaleza, primero revisaremos algunas anotaciones sobre estos puntos; puesto que, en la reflexión kantiana, en ambos encontramos belleza. Veamos primero las distinciones que el filósofo realiza sobre el arte.

\section{§ 3.2. El arte en la reflexión estética kantiana}

En el §43, Kant señala que, en general, el arte es un tipo de producción que se realiza por libertad, es decir, es producto del libre arbitrio; es un tipo de actividad consciente en la cual el artista produce una obra con miras a una prefiguración de la obra concluida, es decir, atendiendo al fin de lo que él haya querido que la obra sea. La obra de arte es, de esta manera, distinta de un objeto natural puesto que, sobre estos últimos no se podría decir que la naturaleza los haya producido de manera consciente, esto es, con vistas a un fin. Posteriormente, continúa su especificacióny establece aquello que entiende por arte bello. De este modo, señala que el arte se distingue de la ciencia en tanto que este no es un tipo de saber teorético, como si al desentrañar paso a paso el proceso seguido en una determinada realización, se estuviese en condiciones de realizarla nuevamente.

Ahora bien, aún cuando se distinga tanto de la ciencia, por no tratarse de un saber estrictamente teórico, el arte está sujeto a ciertas reglas, así dirá: "es imprescindible un elemento compulsorio o, como se lo llama, un mecanismo (por ejemplo, en el arte poético, la exactitud, la riqueza del lenguaje, al igual que la prosodia y la medida de las sílabas), sin el cual el espíritu, que debe ser libre en el arte, y es el único que vivifica la obra, no tendría cuerpo alguno y se evaporaría completamente"|7.

\footnotetext{
16 lbid., § 9, B29.

17 Ibid., § 43, BI76.
} 
Luego señala que debemos advertir la diferencia entre arte mecánico y arte estético; el primero está sujeto a la observancia de reglas para su realización. Este, pues, a diferencia del segundo, place mediante concepto, a saber de aquello que deba ser el objeto de acuerdo a la observancia de ciertas reglas. El arte estético, por otro lado, se divide a su vez en arte agradable y arte bello; aquel suscita placer únicamente asociado a las sensaciones y este tiene por propósito inmediato el sentimiento del placer $^{18}$.

Las indicaciones anteriores se encuentran asociadas a la siguiente distinción. Esta última será una de las más importantes definiciones que Kant realice respecto del arte bello, a saber, aquel que es propio de la indagación estética. Él distingue aquí entre belleza adherente y belleza libre. La primera es aquella en la cual se plantea un concepto de lo que deba ser el objeto de la representación, así, por ejemplo, el concepto de un hombre bello o de una iglesia; se coloca así un ideal de belleza que aquel que juzga obtiene por abstracción de casos similares. Sin embargo, en el segundo, en el momento en que se juzga, no se concibe un concepto de aquello que deba ser el objeto de la representación. Es decir, la complacencia es inmediata, no está mediada por ningún concepto de aquello que deba ser el objeto de la representación. La complacencia se da meramente en la forma. A saber, únicamente en la idoneidad del objeto para ser juzgado mediante nuestras facultades de conocimiento. En ese juicio ellas -imaginación y entendimiento- concuerdan simplemente en un libre juego.

\section{§ 3.3. La belleza natural}

Veamos ahora las consideraciones que Kant realiza sobre la belleza en la naturaleza. En el § 23, que abre la parte del libro titulada "Analítica de lo sublime”, Kant nos indica cómo es que se juzga bella la naturaleza: "la belleza natural [...] conlleva en sí una conformidad a fin en su forma, a través de la cual el objeto parece, por decirlo así, predestinado para nuestra facultad de juzgar y constituye en sí, de ese modo, un objeto de la complacencia"|9. Más adelante añade: "la belleza natural independiente nos descubre una técnica de la naturaleza que la hace presentable como un sistema según leyes, cuyo 
principio no hallamos en nuestra facultad del enjuiciamiento, a saber, como el de una conformidad a fin que es respectiva del uso de la facultad de juzgar en referencia a los fenómenos, de manera que estos tienen que ser juzgados, no solo como pertenecientes a la naturaleza en su mecanismo desprovisto de finalidad, sino también como pertenecientes a la analogía con el arte. Aquella amplía, pues, efectivamente, no nuestro conocimiento de los objetos naturales, pero sí nuestro concepto de naturaleza, a saber, desde el simple mecanismo al concepto de aquella misma como arte: lo que invita a hondas indagaciones sobre la posibilidad de una tal forma" 20 .

Así pues, cuando de lo que se trata es de la belleza en la naturaleza, el objetivo no es buscar un conocimiento de aquello que es la naturaleza con miras a un conocimiento de esta, es decir, no es un juicio de conocimiento, sino un juicio de gusto. Además, en el pasaje anterior, tenemos que aquel que contempla la belleza natural encuentra en su acercamiento a esta que hay una afinidad entre él y la naturaleza. Encuentra, por decirlo así, que esta está predestinada para nuestra facultad de juzgar y, finalmente, y más importante, en tanto que plantea la relación de esta con el arte, tiene que pensarla como perteneciente a la analogía con el arte. Así, alimenta un interés intelectual en esta, pues al pensarla como arte, es decir, como un producto, invita a hondas indagaciones sobre la posibilidad de una tal forma ${ }^{21}$.

\section{$\S$ 3.4. La relación entre arte y naturaleza}

Entremos, ahora, a la relación entre naturaleza y arte. En el $\S 45$, Kant señala que bien sea en la naturaleza o bien sea en el arte, bello es aquello que place en el mero enjuiciamiento (no en la sensación de los sentidos ni a través de un concepto).

Como ya se anotó anteriormente, bella es la naturaleza cuando tiene viso de arte. Es decir, la naturaleza aparece ante nosotros (aún siéndonos imposible descifrar algunas supuestas reglas a través de las cuales se constituye) como si tuviera una conformidad tal que puede ser juzgada por nosotros. Así,

\footnotetext{
${ }^{20} \mathrm{lbid} .$, § 23, B77-78.

${ }^{21}$ Cf. ibid.
} 
hacemos una analogía con el arte bello. Es decir como una actividad realizada a la manera de una producción.

Por otro lado, el arte bello, para ser considerado como tal, tiene que parecer, a su vez, naturaleza; tiene que serlo en el sentido de que debe parecer "tan libre de toda sujeción a reglas intencionales como si fuera un producto de la mera naturaleza" 22 . Sin embargo, como ya señalamos, las reglas en el arte son necesarias pues es "requerible un elemento compulsorio [...] un mecanismo sin el cual el espíritu, que debe ser libre en el arte y es el único que vivifica la obra, no tendría cuerpo alguno y se evaporaría completamente"23. Así, estas reglas deben aparecer en la obra sin que la forma académica trasluzca, sin mostrar que la regla haya constreñido al artista de tal forma que este haya puesto "trabas a sus fuerzas del ánimo".

Esta reflexión sobre la relación entre naturaleza y arte tiene por base aquello que posee en común arte bello y bella naturaleza, a saber, que a ambas se juzga mediante un juicio de gusto estético. Así, sobre el "sentimiento de libertad en el juego de nuestras facultades de conocimiento, que, empero, tienen que ser a la vez conformes a fin, descansa ese placer, que es lo único universalmente comunicable, sin fundarse, no obstante, en conceptos" ${ }^{24}$.

Sin embargo, para que la obra de arte sea tal, es decir, para que aún siendo un trabajo ceñido a reglas ( $y$ que necesariamente tiene por fundamento de determinación un concepto) parezca haber sido realizada sin haber observado ninguna norma de la academia (de tal modo que logre semejar naturaleza), el artista debe ser capaz de producir dicha obra de una manera muy singular. Este proceder será lo que determine aquello que haya de llamarse arte bello. Veamos detenidamente este último aspecto pues será lo que conecte a la naturaleza con el arte y explique el modo en el que se produce el sentimiento de lo bello.

22 Ibid., § 45, BI79.

${ }^{23}$ lbid., § 43, BI76. 


\section{$\S$ 3.5. El genio del artista}

En el §46, Kant señala que el arte bello es el arte producido por el genio. Este vincula a la naturaleza y al arte puesto que genio "es la innata disposición del ánimo (ingenium) a través de la cual la naturaleza le da la regla al arte" 25 . Como ya se señaló, el arte bello no puede tener una regla que tenga por fundamento de determinación un concepto y así tampoco un concepto que haya de indicar la manera en que la obra deba ser realizada, pues, si no, el juicio de gusto ejercido en el producto artístico tendría a su vez que ser derivado de un tal concepto, y siendo así no sería un juicio sobre la belleza. Es por ello que la regla, requerida para que la obra pueda ser considerada como arte bello, es dada por la naturaleza a través del genio ${ }^{26}$. Kant define al genio como un talento para producir aquello para lo cual no se puede dar ninguna regla determinada y que, además, no puede ser aprendido según una regla. Luego, las obras del genio deben ser ejemplares pues, aun cuando pueda haber un sinsentido original, deben servir de modelo, no de imitación, sino como criterio o regla de enjuiciamiento. Además, el artista genial no puede explicar cómo pone su obra en pie; así, su talento es particular porque no puede hacer partícipe a otro mediante una explicación de aquello que ha puesto en obra para que este otro haga una producción similar. Finalmente, señala que el genio es un talento a través del cual la naturaleza prescribe la regla al arte, y no a la ciencia ${ }^{27}$.

Así, también, la regla que da el genio al arte no puede ser redactada en una fórmula, en la medida en que esta no es conceptual; la regla, pues, debe ser abstraída del mismo producto y puede servir, a manera de sucesión, como modelo a aquellos que deseen probar sus propias habilidades en la ejecución de sus obras.

Sin embargo, el arte no es un mero producto del azar, necesariamente la obra tiene en su ejecución algo pensado como finalidad para que logre constituirse en tal. Así, el arte requiere de ciertas reglas porque, como Kant señala, "el genio no puede proporcionar más que rico material para productos del arte

\footnotetext{
${ }^{25}$ Ibid., § 46, BI8I.

${ }^{26}$ Cf. ibid., § 46 .

${ }^{27}$ Cf. ibid.
} 
bello" ${ }^{28}$. Es labor de la academia dar forma a ese material y lograr que este encuentre el sentido necesario para que la obra pueda ser sostenida por la facultad de juzgar, puesto que, es esta última la que vincula la producción artística con la obra de arte. La facultad de juzgar sirve como contrapeso de la obra. El arte no puede ser producto del mero impulso libre de las fuerzas del ánimo, "sino de mejoramiento lento y penoso para hacer que esa tal forma llegue a ser adecuada al pensamiento" ${ }^{29}$ sin que, a su vez, este trabajo perjudique a las fuerzas del ánimo.

Es bajo estas condiciones que el arte alcanza a ser considerado como arte bello. Pero, además, resulta necesario establecer qué es aquello que caracteriza a ambos -naturaleza y arte bello-en una vinculación tal, que pone a este último como capacitado para mover al ánimo, de tal forma que ninguna otra actividad humana podría hacerlo. Recordemos que también Mendelssohn consideraba que existía un elemento que vinculaba el arte y la naturaleza de tal modo que ambas eran capaces de mover el ánimo como nada puede hacerlo. Para él, este elemento era la perfección que el artista era capaz de abstraer de las formas semejantes en la naturaleza y la plasmaba en sus obras. Kant, como veremos, seguirá un camino distinto.

Él señala que acerca de la belleza natural surge un peculiar interés inmediato que consiste en un interés por la belleza en tanto que ha sido encontrada en la naturaleza, no así en alguna imitación que pretenda ser naturaleza. Cuando se descubre que es imitación y no naturaleza, el interés inmediato desaparece y solo queda un interés en estos como objeto para fines particulares (el ornato, por ejemplo) ${ }^{30}$. Recordemos que Mendelssohn también señala cómo es que cuando se toma el arte como si fuese naturaleza, primero se siente un interés, pero, cuando se cae en la cuenta de que es sólo una imitación de la naturaleza, se pierde todo el interés en dicha obra. Es más bien el arte tenido no como imitación, sino como producción lo que para Mendelssohn es importante destacar en el momento de la apreciación del arte bello. Claro está, para él, la obra de arte, es decir, la obra del genio, debe ser realizada en vista al ideal de perfección en la naturaleza. La producción del genio, aun cuando no imite a

\footnotetext{
${ }^{28}$ Ibid., § 47, BI86.

${ }^{29}$ Ibid., § 48, B190-I9I.

${ }^{30}$ Cf. ibid., § 42 .
} 
los objetos de la naturaleza, debe estar mediada por el concepto de perfección abstraído de su observación de la naturaleza.

Kant, por el contrario, aísla de su teoría estética toda sujeción a conceptos. Así, tanto para el ejercicio del gusto en la naturaleza y en el arte, como también en la producción artística, la mediación de un concepto es inconcebible. Recordemos pues que la facultad de juzgar estética señala, únicamente, una complacencia en la forma, más no en el contenido de la representación. Es la concordancia en el libre juego entre imaginación y entendimiento lo que permite que se pueda señalar que un objeto es bello. La idea de que el arte tenga que imitar a la naturaleza está completamente descartada en la posición kantiana. Él señala, más bien, que el arte debe semejar naturaleza, tanto como la naturaleza debe ser tomada en analogía con el arte, como una producción, si es que puede ser juzgada bella. Aquello que liga a ambas no es su identidad como pretendiendo que la imitación sea el fin del arte, sino, más bien, lo que las liga depende de aquello que ellas comparten: belleza.

\section{§ 3.6. La belleza y las ideas estéticas en la reflexión estética kantiana}

Veamos, finalmente, de manera directa aquello que de manera específica arte y naturaleza comparten, es decir, la belleza. En el §5। Kant señala: “la belleza (sea ella belleza natural o belleza artística) puede ser llamada en general expresión de ideas estéticas" ${ }^{31}$. Una idea estética es "una representación de la imaginación asociada a un concepto dado, la cual está ligada a una multiplicidad tal de representaciones parciales, que no se puede hallar para ellas mismas ninguna expresión que designe un concepto determinado y que deja, pues, pensar a propósito de un concepto mucha cosa innominable, el sentimiento de lo cual vivifica las facultades de conocimiento, $y$ al lenguaje, en cuanto mera letra, asocia el espíritu"32.

Antes de dar esta definición, Kant ya indicó en el § 49 que: "Espíritu en acepción estética, significa el principio vivificante en el ánimo" ${ }^{33}$, y el principio a

\footnotetext{
${ }^{31}$ Ibid., § 5I, B204.

32 lbid., § 49, BI97.

${ }^{33}$ lbid., § 49, BI92.
} 
través del cual el espíritu vivifica el ánimo es la facultad de presentación de ideas estéticas. Notamos una diferencia radical respecto de las formulaciones mendelssohnianas, puesto que él consideraba que la perfección de la naturaleza que el artista imita en sus obras al plasmarlas en una representación sensible, es aquello que vivifica el ánimo. Respecto de las ideas estéticas, Kant señala: "bajo idea estética entiendo aquella representación de la imaginación que da ocasión a mucho pensar, sin que pueda serle adecuado, empero, ningún pensamiento determinado, es decir, ningún concepto, ni tampoco ningún lenguaje puede plenamente alcanzar ni hacer comprensible" ${ }^{34}$; esta es la contraparte de una idea de la razón que es un concepto al que no puede serle adecuada ninguna intuición.

Es esta capacidad de expresar ideas estéticas la que singulariza al genio como creador y no como imitador. Recordemos que, a través del genio, la naturaleza le da la regla al arte, $y$, en las producciones artísticas, esto es, en la producción de ideas estéticas, el genio hace que el espectador ponga en obra su facultad de juzgar estética.

Así, también, en la naturaleza, la transmisión de ideas estéticas es lo que hace que, cuando se contempla la belleza natural, se exhiba la conformidad a fin sin fin en el juego de las facultades de conocimiento. Es esta conformidad a fin la que lleva al ser humano que contempla a hondas indagaciones sobre la posibilidad de una tal forma.

Dentro del marco de su investigación crítica — que incluye la Crítica de la razón pura y la Crítica de la razón práctica-, en la Crítica de la facultad de juzgar Kant vincula la reflexión anterior con la destinación moral del individuo. Sin embargo, la exploración de dicho recorrido sale del margen la intención de esta investigación. Lo que aquí hemos procurado es revisar algunos conceptos clave dentro del panorama de la reflexión sobre la estética en la llustración, y de modo particular la manera en la que Kant tematiza en qué consiste la experiencia de lo bello. Con relación a esto también hemos buscado esclarecer cuáles son aquellos talentos que singularizan el trabajo artístico. 